\title{
Responses of the ambulatory arterial stiffness index and other measures of arterial function to antihypertensive drugs
}

\author{
Yu Jin ${ }^{1}$, Lutgarde Thijs ${ }^{1}$, Tom Richart ${ }^{1,2}$, Yan $\mathrm{Li}^{3}$, Eamon Dolan ${ }^{4}$, Ji-Guang Wang ${ }^{5}$, Athanase Protogerou ${ }^{6}$, \\ Eoin O’Brien ${ }^{7}$, Jan A Staessen ${ }^{1,2}$ and Michel E Safar ${ }^{8}$, on behalf of the REASON Investigators
}

We investigated the effects of different antihypertensive drugs on the ambulatory arterial stiffness index (AASI), pulse pressure (PP), the arterio-ventricular coupling index (AVCl) and aortic pulse wave velocity (aPWV). After a 4-week placebo period, 94 and 107 patients with uncomplicated hypertension were randomly assigned to treatment with atenolol (AT) at dosage of $50 \mathrm{mg}$ per day or perindopril/indapamide (PER/IND) at dosage of $2 / 0.6 \mathrm{mg}$ per day for 1 year. From each patient's 24-h ambulatory blood pressure (BP) recording, we determined the 24-h systolic and diastolic BPs. We computed PP as the difference between 24-h systolic and diastolic BP, AASI as unity minus the regression slope of diastolic on systolic BP, and AVCI as $(T / \tau) /(1+2 T / 3 \tau)$, where $T$ is the heart period in seconds and $\tau$ is the decay time of aortic BP during diastole. On AT compared with PER/IND, with adjustments applied for covariables, 24-h systolic BP $(-9.5$ vs. $-13.7 \mathrm{~mm} \mathrm{Hg} ; P=0.009)$ and $24-\mathrm{h}$ PP $(-1.02$ vs. $-6.53 \mathrm{~mm} \mathrm{Hg} ; P<0.001)$ decreased less and AVCI lengthened more $(+0.019 \mathrm{vs} .-0.008 ; P<0.001)$. The changes in AASI ( -0.001 vs. $-0.014 ; P=0.44)$ and aPWV $\left(-0.89\right.$ vs. $\left.-0.69 \mathrm{~m} \mathrm{~s}^{-1} ; P=0.45\right)$ were similar in the two treatment groups. AASI and aPWV showed significant concordance $(r=0.21, P=0.003)$ after adjustment for covariables. On administration of antihypertensive drugs with different hemodynamic profiles, AASI and aPWV behaved similarly. The similarity in the findings for aPWV and AASI support the use of AASI as an index reflecting the arterial stiffness.

Hypertension Research (2011) 34, 489-495; doi:10.1038/hr.2010.256; published online 13 January 2011

Keywords: ambulatory arterial stiffness index; ambulatory blood pressure; aortic pulse wave velocity; arterial stiffness

\section{INTRODUCTION}

The ambulatory arterial stiffness index (AASI) has been defined as one minus the regression slope of diastolic on systolic blood pressure, as measured at the brachial artery by 24 -h ambulatory blood pressure (BP) monitoring. ${ }^{1,2}$ AASI reflects the dynamic relation between diastolic and systolic BPs throughout the whole day. Conceptually consistent with a hypothesis put forward in $1914,{ }^{3}$ the stiffer the arterial tree, the closer the regression slope and AASI are to zero and one, respectively. Measurement of AASI does not require any other equipment than a validated ${ }^{4}$ portable monitor to record 24 -h blood pressure. To date, cross-sectional analyses ${ }^{5}$ and at least three prospective cohort studies ${ }^{2,6,7}$ have demonstrated an association of AASI either with signs of target organ damage in never-treated hypertensive patients, ${ }^{5}$ or with the incidence of cardiovascular mortality and morbidity. ${ }^{2,6,7}$
AASI has been criticized as being merely a surrogate measure ${ }^{8-10}$ that may reflect hemodynamic factors such as arterio-ventricular coupling ${ }^{10}$ rather than arterial stiffness. More direct measurements of arterial stiffness, ${ }^{8}$ in particular aortic pulse wave velocity (aPWV), have a large amount of epidemiological evidence supporting the predicate that they predict cardiovascular events. ${ }^{11}$ The aPWV is usually considered as the gold standard for the assessment of arterial stiffness ${ }^{8}$ and might be helpful in elucidating further the physiological meaning of AASI. For this purpose, we analyzed the REASON trial (Preterax in Regression of Arterial Stiffness in a Controlled Double-Blind Study). ${ }^{12-14}$ We compared the effects of antihypertensive treatment with either atenolol (AT) or the combination of perindopril plus indapamide (PER/IND) on AASI, aPWV and pulse pressure (PP).

\footnotetext{
1Studies Coordinating Centre, Laboratory of Hypertension, Division of Hypertension and Cardiovascular Rehabilitation, Department of Cardiovascular Diseases, University of Leuven, Leuven, Belgium; ${ }^{2}$ Department of Epidemiology, Maastricht University, Maastricht, The Netherlands; ${ }^{3}$ Center for Vascular Evaluation, Shanghai Key Laboratory of Vascular Biology, Ruijin Hospital, Shanghai Jiaotong University Medical School, Shanghai, China; ${ }^{4}$ Hypertension Unit, Connolly Hospital, Dublin, Ireland; ${ }^{5}$ Centre for Epidemiological Studies and Clinical Trials, Ruijin Hospital, Shanghai Institute of Hypertension, Shanghai Jiaotong University Medical School, Shanghai, China; ${ }^{6}$ Hypertension Center, First Department of Propaedeutic Medicine, Laiko Hospital, Medical School, National and Kapodistrian University of Athens, Athens, Greece; ${ }^{7}$ Conway Institute of Biomolecular and Biomedical Research, University College Dublin, Dublin, Ireland and ${ }^{8}$ Diagnosis Centre, Hôtel-Dieu Hospital, Faculty of Medicine, Paris-Descartes University, Paris, France Correspondence: Dr JA Staessen, Studies Coordinating Centre, Laboratory of Hypertension, Division of Hypertension and Cardiovascular Rehabilitation, Department of Cardiovascular Diseases, University of Leuven, Campus Sint Rafaël, Kapucijnenvoer 35, Block d, Level 00, Box 7001, B-3000 Leuven, Belgium. E-mails: jan.staessen@med.kuleuven.be or jan.staessen@epid.unimaas.nl
}

Received 16 August 2010; revised 24 September 2010; accepted 12 October 2010; published online 13 January 2011 


\section{METHODS}

\section{Study population}

The REASON trial was a multicenter, randomized, double-blind and parallel-group study conducted in 13 countries. It compared the hemodynamic effects of the low-dose combination PER/IND with those of AT. Eligible patients had uncomplicated essential hypertension. Their BP measured in the supine position in the absence of any cardiovascular, antidiabetic or lipid-lowering drugs had to range from 160 to $209 \mathrm{~mm} \mathrm{Hg}$ systolic or from 95 to $109 \mathrm{~mm} \mathrm{Hg}$ diastolic. The present article reports on an ancillary study involving 32 of the 52 REASON centers, ${ }^{12-14}$ which opted to perform ambulatory BP monitoring (ABPM). Of 471 REASON patients, 269 underwent ABPM. A valid ambulatory recording had to include at least 48 measurements over $24 \mathrm{~h}$ and the interval between two successive readings should not be longer than $1 \mathrm{~h}$. We excluded 68 patients, because their ambulatory BP recording at baseline or follow-up was of insufficient quality, leaving 201 patients for the present analysis. All patients gave written informed consent. The study was conducted in accordance with the Declaration of Helsinki after ethical approval had been obtained from the national regulatory authorities of each of the countries.

\section{Treatment}

After a 4-week placebo washout period, the patients were randomly assigned to treatment for 1 year, with PER ( $2 \mathrm{mg}$ per day) plus IND ( $0.625 \mathrm{mg}$ per day), or AT (50 mg per day) to be taken in the morning. After 3, 6 or 9 months, treatment could be adjusted according to the office BP measurements. If systolic or diastolic BP or both were higher than 160 or $90 \mathrm{~mm} \mathrm{Hg}$, the dose of the study medication was increased to two tablets, both to be taken in the morning. During follow-up, patients abstained from taking other BP-lowering drugs.

\section{Blood pressure measurement}

Conventional BP was measured at the brachial artery after the patients had rested for $10 \mathrm{~min}$ in the supine position, using a standard mercury sphygmomanometer and a suitable cuff size. The devices used for ABPM passed validation in class A or B, according to the protocols of the British Hypertension Society ${ }^{15}$ or the Association for the Advancement of Medical Instrumentation. ${ }^{16}$ We programed the recorders to obtain readings at 15 -min intervals throughout the whole day, with the first measurement taken between 0800 and $1000 \mathrm{~h}$, just before the intake of the study medication. We standardized the ambulatory recordings; at baseline and after 1 year of follow-up; ${ }^{14}$ the same technician applied the same monitor to the same arm in each patient and at the same time $( \pm 1 \mathrm{~h})$ in the morning.

Pulse pressure, the difference between systolic and diastolic BP, and mean arterial pressure, diastolic BP plus one-third of PP, were computed from the office and the 24-h ambulatory BPs. Blood pressure control on conventional measurement was a systolic BP of less than $140 \mathrm{~mm} \mathrm{Hg}$ and a diastolic BP below $90 \mathrm{~mm} \mathrm{Hg}$. The BP control on ambulatory measurement was a 24-h systolic BP below $125 \mathrm{~mm} \mathrm{Hg}$ and a 24-h diastolic BP of less than $75 \mathrm{~mm} \mathrm{Hg} .{ }^{17}$

\section{Measurement of arterial properties}

At baseline and after 1 year of follow-up, we measured aPWV in the morning, after conventional BP measurement, and approximately $24 \mathrm{~h}$ after the last drug intake in a controlled environment at a mean (s.d.) temperature of $22 \pm 2{ }^{\circ} \mathrm{C},{ }^{12}$ with the Complior (Colson, Paris, France). This device allows online pulse wave recording and the automated calculation of aPWV, and has been validated against the manual method. ${ }^{17}$ The mean difference between the two methods was $-0.20 \pm 0.45 \mathrm{~m} \mathrm{~s}^{-1}$ (manual method, $11.05 \pm 2.58 \mathrm{~m} \mathrm{~s}^{-1}$ vs. automatic device $\left.10.85 \pm 2.44 \mathrm{~m} \mathrm{~s}^{-1}\right)$. The interobserver repeatability coefficient was 0.947 for the manual aPWV measurements and 0.890 for the Complior; for the intraobserver repeatability coefficients, these estimates were 0.938 and 0.935 , respectively.

From individual 24-h ambulatory BP recordings, we computed the regression slope of diastolic on systolic BP. ${ }^{1,2}$ We defined AASI as one minus the regression slope. We did not force the slope through the origin (intercept $=0$ ), because when during diastole the blood flow falls to zero, this does not occur for BP. ${ }^{18}$ From the individual readings in each 24-h ambulatory BP recording, we also computed the arterioventricular coupling index $(\mathrm{AVCI})$ as $(\mathrm{T} / \tau) /(1+2 \mathrm{~T} / 3 \tau),{ }^{10}$ where $\mathrm{T}$ is the heart period in seconds and $\tau$ is the decay time of aortic BP during diastole. ${ }^{10,19}$ We computed $\tau$ as $(60 \times$ mean arterial pressure $) /($ heart rate $\times \mathrm{PP})$.

\section{Other measurements}

We measured body weight without shoes, with the subjects wearing light indoor clothing. Body mass index was weight in kilograms divided by height in meters squared. Using $<25 \mathrm{~kg} \mathrm{~m}^{-2}, 25-$ $30 \mathrm{~kg} \mathrm{~m}^{-2}$ and $\geqslant 30 \mathrm{~kg} \mathrm{~m}^{-2}$ as thresholds, subjects were classified into normal weight, overweight and obese, respectively. We applied the NCEP-ATPIII criteria ${ }^{20}$ to define the metabolic syndrome (MS). Venous blood samples, collected after overnight fasting, were analyzed for blood glucose and the serum concentrations of high-density lipoprotein (HDL) cholesterol and triglycerides by automated enzymatic methods.

\section{Statistical analysis}

For database management and statistical analysis, we used SAS software, version 9.1.3 (SAS Institute, Cary, NC, USA). We compared means and proportions by the large sample $z$-test and by the $\chi^{2}$ statistic, respectively. We compared treatment-induced changes in $\mathrm{BP}$ between the two groups, while adjusting for baseline values, sex, age and body mass index. We searched for possible covariables of the arterial outcome variables by a stepwise multiple regression analysis with the $P$-value for independent variables to enter and stay in the model set at 0.15 . The baseline variables considered for entry into the models were sex, age, body weight and height, 24-h mean arterial BP and 24-h pulse rate, smoking $(0,1)$, intake of alcohol $(0,1)$, previous antihypertensive treatment $(0,1)$ and the presence of the MS $(0,1)$. Analysis of covariance was used to compare the treatment-induced changes between the two treatment groups, while adjusting for baseline and covariables. We used correlation coefficients, unadjusted and adjusted for covariables, to express concordance between the indexes of arterial stiffness.

\section{RESULTS}

\section{Baseline characteristics}

The 201 patients were enrolled in nine countries (France, $n=52$; Australia, $n=50$; Spain, $n=38$; Ireland, $n=22$; Germany, $n=16$; Switzerland, $n=7$; Belgium, $n=6$; Austria, $n=5$; The Netherlands, $n=5$ ). The patients randomized to PER/IND $(n=107)$, compared with those allocated to AT $(n=94)$, included a slightly larger proportion of drinkers (60.8 vs. $58.5 \%$; $P=0.04)$, but had lower HDL-cholesterol levels $\left(1.26\right.$ vs. $\left.1.37 \mathrm{mmoll}^{-1} ; P=0.01\right)$. For the rest, the two treatment groups were well matched in terms of anthropometrics, smoking habits and metabolic abnormalities (Table 1). 
Table 1 Patient characteristics at entry

\begin{tabular}{|c|c|c|c|}
\hline Characteristic & Atenolol & $\begin{array}{l}\text { Perindopril/ } \\
\text { indapamide }\end{array}$ & $\mathrm{P}$-value \\
\hline Number & 94 & 107 & \\
\hline \multicolumn{4}{|l|}{ Anthropometrics } \\
\hline Women, $n(\%)$ & $31(33.0)$ & 32 (29.9) & 0.64 \\
\hline Age, years & $56.8 \pm 13.4$ & $54.5 \pm 11.4$ & 0.19 \\
\hline Weight, kg & $75.2 \pm 11.1$ & $77.4 \pm 11.1$ & 0.15 \\
\hline Height, $\mathrm{cm}$ & $167.3 \pm 8.8$ & $169.3 \pm 8.6$ & 0.11 \\
\hline Body mass index, $\mathrm{kg} \mathrm{m}^{-2}$ & $26.8 \pm 2.5$ & $26.9 \pm 2.8$ & 0.60 \\
\hline Waist-to-hip ratio & $0.92 \pm 0.11$ & $0.92 \pm 0.10$ & 0.52 \\
\hline \multicolumn{4}{|l|}{ Lifestyle } \\
\hline Current smokers, $n(\%)$ & $18(19.2)$ & $23(21.5)$ & 0.70 \\
\hline Current drinkers, $n(\%)$ & $55(58.5)$ & $65(60.8)$ & 0.04 \\
\hline \multicolumn{4}{|l|}{ Biochemical measurements } \\
\hline Glucose, $\mathrm{mmol}^{-1}$ & $5.50 \pm 0.84$ & $5.60 \pm 0.95$ & 0.36 \\
\hline HDL cholesterol, mmol ${ }^{-1}$ & $1.37 \pm 0.30$ & $1.26 \pm 0.34$ & 0.01 \\
\hline Triglycerides, mmol ${ }^{-1}$ & $1.49 \pm 0.70$ & $1.60 \pm 0.80$ & 0.30 \\
\hline \multicolumn{4}{|l|}{ Metabolic abnormalities } \\
\hline Overweight, $n(\%)$ & $62(66.0)$ & $71(66.4)$ & 0.95 \\
\hline Obese, $n(\%)$ & $10(10.6)$ & $10(9.4)$ & 0.95 \\
\hline Metabolic syndrome, $n(\%)$ & $22(23.4)$ & $33(30.8)$ & 0.24 \\
\hline
\end{tabular}

Abbreviation: HDL, high density lipoprotein.

Values are shown as mean \pm s.d. or number of subjects (\%). Body mass index is weight in kilograms divided by the square of height in meters. The waist-to-hip ratio is the smallest circumference at the waist divided by the largest circumference at the hip. Overweight and obesity are body mass indexes of $25-30 \mathrm{~kg} \mathrm{~m}^{-2}$ or $\geqslant 30 \mathrm{~kg} \mathrm{~m}^{-2}$, respectively. $P$-values are for the differences between the two randomized groups.

At randomization (Table 2), the two treatment groups had similar mean levels of systolic and diastolic BPs, as measured by a conventional sphygmomanometry ( $P=0.54$ for systolic and 0.88 for diastolic) or by a 24 -h ambulatory monitoring $(P=0.70$ for systolic and 0.35 for diastolic). In 201 patients, pulse rate measured at the office or by $24-\mathrm{h}$ ambulatory monitoring averaged ( \pm s.d.) $72.5 \pm 9.8$ and $73.8 \pm 9.8$ beats per minute, respectively, without any difference between the groups $(P=0.84$ and 0.83 for office and ambulatory measurements, respectively). Similarly, at randomization, there were no betweengroup differences in the indexes of arterial function, including the conventional and 24-h PP $(P=0.66$ and 0.74 , respectively), AASI $(P=0.75)$, AVCI $(P=0.53), \tau(P=0.57)$ and aPWV $(P=0.84$; Table 3).

\section{Determinants and concordance of the arterial measurements}

In stepwise regression analysis, age, 24-h mean arterial pressure and pulse rate explained $46 \%$ of the variation in the $24-\mathrm{h}$ PP. The same covariables plus body height explained $42 \%$ of the variance in aPWV. Of the variation in AASI, $25 \%$ was explained by age. Age plus the $24-\mathrm{h}$ pulse rate explained 42 and $39 \%$ of the variation in AVCI and $\tau$, respectively (Table 4 ).

Both without adjustment and adjusted for sex, age, body height, 24-h mean arterial pressure and 24-h heart rate, there was significant concordance between PP, AASI and aPWV (Table 5). We did not include AVCI and $\tau$ in Table 5, because for purely computational reasons, these measurements showed spuriously high correlation coefficients with one another and with $24-\mathrm{h}$ PP. ${ }^{10}$
Table 2 Blood pressure at randomization and follow-up

\begin{tabular}{|c|c|c|c|c|}
\hline & Atenolol & $\begin{array}{l}\text { Perindoprill } \\
\text { indapamide }\end{array}$ & $\begin{array}{l}\text { Mean difference } \\
\text { (95\% confidence } \\
\text { interval) }\end{array}$ & P-value \\
\hline Number of patients & 94 & 107 & & \\
\hline \multicolumn{5}{|l|}{ Systolic blood pressure } \\
\hline \multicolumn{5}{|l|}{ Conventional office } \\
\hline Randomization & $160.9 \pm 15.3$ & $162.1 \pm 13.1$ & $-1.22(-5.17$ to 2.73$)$ & 0.54 \\
\hline Change & $-16.9 \pm 13.4^{\ddagger}$ & $-22.6 \pm 13.9^{\ddagger}$ & 5.61 (1.68 to 9.55$)$ & 0.005 \\
\hline Adjusted change & $-17.8 \pm 12.8^{\ddagger}$ & $-21.8 \pm 12.2^{\ddagger}$ & $3.99(0.44$ to 7.54$)$ & 0.027 \\
\hline \multicolumn{5}{|l|}{ 24-h ambulatory } \\
\hline Randomization & $143.0 \pm 14.9$ & $143.7 \pm 14.4$ & $-0.79(-4.86$ to 3.29$)$ & 0.70 \\
\hline Change & $-9.3 \pm 13.0^{\ddagger}$ & $-13.9 \pm 11.8^{\ddagger}$ & 4.62 (1.15 to 8.08$)$ & 0.009 \\
\hline Adjusted change & $-9.5 \pm 11.3^{\ddagger}$ & $-13.7 \pm 11.3^{\ddagger}$ & 4.24 (1.07 to 7.41$)$ & 0.009 \\
\hline
\end{tabular}

Conventional office

Randomization $\quad 97.6 \pm 8.1 \quad 97.8 \pm 7.5 \quad-0.16(-2.34$ to 2.01$) \quad 0.88$

Change $\quad-13.8 \pm 7.2^{\ddagger} \quad-12.9 \pm 8.3^{\ddagger} \quad-0.92(-3.17$ to 1.32$) \quad 0.42$

Adjusted change $\quad-13.8 \pm 7.4^{\ddagger} \quad-13.0 \pm 7.1^{\ddagger} \quad-0.86(-2.89$ to 1.18$) \quad 0.41$

24-h ambulatory

Randomization $\quad 86.6 \pm 10.0 \quad 88.0 \pm 10.2 \quad-1.33(-4.15$ to 1.48$) \quad 0.35$

Change $\quad-8.4 \pm 7.8^{\ddagger} \quad-7.3 \pm 7.3^{\ddagger} \quad-1.11(-3.20$ to 0.97$) \quad 0.29$

Adjusted change $\quad-8.6 \pm 6.4^{\ddagger} \quad-7.12 \pm 6.4^{\ddagger} \quad-1.46(-3.26$ to 0.34$) \quad 0.11$

$\begin{array}{lccrc}\begin{array}{c}\text { Mean arterial pressure } \\ \text { Conventional office }\end{array} & & & & \\ \quad \text { Randomization } & 118.7 \pm 7.3 & 119.2 \pm 6.1 & -0.52(-2.37 \text { to } 1.34) & 0.58 \\ \text { Change } & -14.9 \pm 7.3^{\ddagger} & -16.1 \pm 9.0^{\ddagger} & 1.25(-1.07 \text { to } 3.58) & 0.30 \\ \quad \text { Adjusted change } & -15.1 \pm 8.2^{\ddagger} & -15.9 \pm 7.8^{\ddagger} & 0.87(-1.39 \text { to } 3.14) & 0.45 \\ \text { 24-h ambulatory } & & & & \\ \text { Randomization } & 105.9 \pm 10.2 & 106.9 \pm 10.6 & -0.94(-3.84 \text { to } 1.96) & 0.52 \\ \text { Change } & -8.6 \pm 9.1^{\ddagger} & -9.7 \pm 8.5^{\ddagger} & 1.17(-1.28 \text { to } 3.62) & 0.35 \\ \text { Adjusted change } & -8.7 \pm 7.8^{\ddagger} & -9.6 \pm 7.8^{\ddagger} & 0.86(-1.32 \text { to } 3.05) & 0.44\end{array}$

Values are shown as mean \pm s.d. Adjusted changes account for baseline value, sex, age, and body mass index. Significance of the within-group changes from baseline: ${ }^{\ddagger} P \leqslant 0.001$.

\section{Effects of treatment on pulse rate and blood pressure}

The baseline-adjusted change in the 24 -h pulse rate averaged ( \pm s.d.) $-11.0 \pm 11.3$ beats per minute in the AT group and $0.4 \pm 7.1$ per minute in the PER/IND group. The baseline-adjusted between-group difference (AT minus PER/IND) and the changes in the 24-h pulse rate amounted to 11.4 beats per minute (95\% confidence interval, -13.3 to $-9.5 ; P<0.001)$.

Systolic BP decreased significantly $(P=0.005)$ more in the PER/IND group than in the patients randomized to AT, irrespective of whether systolic BP was measured at the office or by ABPM (Table 2). Adjustment of the changes in systolic BP for baseline, sex, age and body mass index did not alter these findings. In contrast, the treatment-induced changes in diastolic $\mathrm{BP}(P=0.42)$ and mean arterial pressure $(P=0.30)$ were similar in both the treatment groups (Table 2). After 1 year of treatment, the control rates of hypertension on conventional BP measurement were $80.8 \%$ on AT and $77.6 \%$ on PER/IND; on 24-h ABPM, the control rates were 48.9 and $53.3 \%$, respectively. Those control rates of hypertension showed no difference between the two treatment groups.

\section{Effects of on treatment on arterial function}

In line with the findings for systolic BP, the PP, as measured by conventional sphygmomanometry or ABPM, decreased significantly more on PER/IND than AT dosage (Table 3). As could be expected on 
Table 3 Indexes of arterial function at randomization and follow-up

\begin{tabular}{|c|c|c|c|c|}
\hline & Atenolol & $\begin{array}{l}\text { Perindopril/ } \\
\text { indapamide }\end{array}$ & $\begin{array}{c}\text { Mean difference } \\
\text { (95\% confidence } \\
\text { interval) }\end{array}$ & $\mathrm{P}$-value \\
\hline Number of patients & 94 & 107 & & \\
\hline \multicolumn{5}{|l|}{ Pulse pressure } \\
\hline \multicolumn{5}{|l|}{ Conventional office } \\
\hline Randomization & $63.21 \pm 17.62$ & $64.26 \pm 16.21$ & $-1.05(-5.76$ to 3.65$)$ & 0.66 \\
\hline Change & $-3.09 \pm 13.75^{*}$ & $-9.63 \pm 11.34 \ddagger$ & 6.54 (2.96 to 10.12 ) & $<0.001$ \\
\hline Adjusted change & $-4.22 \pm 9.77^{\ddagger}$ & $-8.70 \pm 9.75^{\ddagger}$ & 4.49 (1.66 to 7.32$)$ & 0.002 \\
\hline \multicolumn{5}{|l|}{ 24-h ambulatory } \\
\hline Randomization & $56.3 \pm 12.1$ & $55.8 \pm 11.6$ & 0.55 ( -2.75 to 3.84$)$ & 0.74 \\
\hline Change & $-0.90 \pm 7.42$ & $-6.63 \pm 6.57^{\ddagger}$ & 5.73 (3.78 to 7.68$)$ & $<0.001$ \\
\hline Adjusted change & $-1.02 \pm 6.42$ & $-6.53 \pm 6.41^{\ddagger}$ & 5.51 (3.70 to 7.31$)$ & $<0.001$ \\
\hline \multicolumn{5}{|l|}{$A A S I$} \\
\hline Randomization & $0.42 \pm 0.17$ & $0.43 \pm 0.16$ & $-0.01(-0.05$ to 0.04$)$ & 0.75 \\
\hline Change & $+0.006 \pm 0.13$ & $-0.019 \pm 0.13$ & $0.02(-0.01$ to 0.06$)$ & 0.17 \\
\hline Adjusted change & $-0.001 \pm 0.12$ & $-0.014 \pm 0.12$ & $0.01(-0.02$ to 0.05$)$ & 0.44 \\
\hline \multicolumn{5}{|l|}{$\mathrm{AVCl}$} \\
\hline Randomization & $0.39 \pm 0.06$ & $0.38 \pm 0.06$ & $0.005(-0.011$ to 0.021$)$ & 0.53 \\
\hline Change & $+0.019 \pm 0.03^{\ddagger}$ & $-0.008 \pm 0.03^{\dagger}$ & 0.027 (0.019 to 0.034$)$ & $<0.001$ \\
\hline Adjusted change & $+0.019 \pm 0.03^{\ddagger}$ & $-0.008 \pm 0.03^{\ddagger}$ & $0.027(0.020$ to 0.035$)$ & $<0.001$ \\
\hline \multicolumn{5}{|l|}{$\tau$} \\
\hline Randomization & $1.69 \pm 0.34$ & $1.72 \pm 0.36$ & $-0.03(-0.13$ to 0.07$)$ & 0.57 \\
\hline Change & $+0.17 \pm 0.26^{\ddagger}$ & $+0.04 \pm 0.21$ & 0.13 (0.07 to 0.19$)$ & $<0.001$ \\
\hline Adjusted change & $+0.16 \pm 0.22^{\ddagger}$ & $+0.04 \pm 0.23$ & $0.12(0.06$ to 0.19$)$ & $<0.001$ \\
\hline \multicolumn{5}{|l|}{$a P W V$} \\
\hline Randomization & $12.4 \pm 2.90$ & $12.3 \pm 2.86$ & $0.08(-0.72$ to 0.89$)$ & 0.84 \\
\hline Change & $-0.87 \pm 2.19^{\ddagger}$ & $-0.72 \pm 2.01^{\ddagger}$ & $-0.15(-0.75$ to 0.45$)$ & 0.62 \\
\hline Adjusted change & $-0.89 \pm 1.91^{\ddagger}$ & $-0.69 \pm 1.85^{\ddagger}$ & $-0.20(-0.73$ to 0.32$)$ & 0.45 \\
\hline
\end{tabular}

Abbreviations: $\tau$, diastolic decay time in aortic pressure; AASI, ambulatory arterial stiffness index; aPWV, aortic pulse wave velocity; AVCI, arterio-ventricular coupling index.

Values are shown as mean \pm s.d. Adjusted changes account for baseline value, sex, age, body height, 24-h mean artery pressure and 24-h pulse rate.

Significance of the within-group changes from baseline: ${ }^{*} P \leqslant 0.05 ;{ }^{\dagger} P \leqslant 0.01 ;{ }^{\ddagger} P \leqslant 0.001$. the basis of the decrease in the 24-h pulse rate and the reciprocal lengthening of the heart period, AVCI and $\tau$ lengthened on AT, with a significant difference in the treatment-induced changes compared with PER/IND (Table 3). aPWV, but not AASI, decreased slightly but significantly on AT as well as PER/IND. However, for both aPWV and AASI, the between-group differences in the treatment-induced changes were far from statistically significant (Table 3). Adjustment of the indexes of arterial function for the baseline values and entry characteristics, including sex, age, body height, 24-h mean arterial pressure and 24-h pulse rate did not materially alter the aforementioned results (Table 3 ).

\section{Sensitivity analyses}

Sensitivity analyses, which additionally accounted for drinking alcohol and the serum level of HDL-cholesterol, confirmed the results reported in Tables 2 and 3 (data not shown). Our findings also remained consistent when we applied robust regression (least trimmed squares), symmetric regression in the computation of AASI, or excluded influential data points $($ DFBETA $>2 / \sqrt{ } n)$.

Because arterial stiffness differs between patients, with and without the MS, ${ }^{21}$ we tested whether the findings in Tables 2 and 3 were influenced by this condition (Figure 1). With adjustments applied as in Table 2, the 24-h systolic BP decreased to the same extent on AT and PER/IND in patients with the MS $(-14.5$ vs. $-11.5 \mathrm{~mm} \mathrm{Hg} P=0.39)$, whereas in patients without the MS, the decrease on AT was smaller than on PER/IND ( -7.9 vs. $-14.8 \mathrm{~mm} \mathrm{Hg} ;=0.003)$. Conversely, in patients with the MS, the adjusted 24-h diastolic BP decreased more on AT than PER/IND $(-13.2$ vs. $-5.8 \mathrm{~mm} \mathrm{Hg} ; P<0.001)$, whereas in patients without the MS these decreases were similar $(-7.2 \mathrm{vs}$. $-7.7 \mathrm{~mm} \mathrm{Hg} ; P=0.58)$. The $P$-values for the interaction between treatment and the MS were $0.006,<0.001$ and $<0.001$ for the $24-\mathrm{h}$ systolic, diastolic and mean arterial pressures, respectively (Figure 1).

Table 4 Determinants of arterial function at baseline in 201 patients

\begin{tabular}{|c|c|c|c|c|c|c|c|c|c|c|}
\hline & 24-h PP (mm Hg) & & AASI (units) & & $\mathrm{AVCl}$ (units) & & $\tau$ (units) & & $a P W V\left(m s^{-1}\right)$ & \\
\hline$R^{2}$ & 0.46 & & 0.25 & & 0.42 & & 0.39 & & 0.42 & \\
\hline \multirow[t]{2}{*}{ Intercept } & -3.36 & & 0.10 & & 0.33 & & 3.48 & & -14.04 & \\
\hline & $\beta \pm$ s.e. & P-value & $\beta \pm$ s.e. & P-value & $\beta \pm$ s.e. & P-value & $\beta \pm$ s.e. & P-value & $\beta \pm$ s.e. & P-value \\
\hline Age $(+10$ years $)$ & $5.349 \pm 0.514$ & $<0.001$ & $0.060 \pm 0.008$ & $<0.001$ & $0.027 \pm 0.309$ & $<0.001$ & $-0.140 \pm 0.015$ & $<0.001$ & $1.555 \pm 0.135$ & $<0.001$ \\
\hline Body height $(+10 \mathrm{~cm})$ & - & - & - & - & - & - & - & - & $0.769 \pm 0.280$ & 0.006 \\
\hline 24-h MBP (+10 mm Hg) & $4.417 \pm 0.610$ & $<0.001$ & - & - & - & - & - & - & $0.415 \pm 0.155$ & 0.008 \\
\hline 24-h pulse rate (+10 beats per $\mathrm{min}$ ) & $-2.353 \pm 0.655$ & $<0.001$ & - & - & $-0.012 \pm 0.003$ & $<0.001$ & $-0.147 \pm 0.019$ & $<0.001$ & $0.413 \pm 0.172$ & 0.017 \\
\hline
\end{tabular}

Abbreviations: $\tau$, diastolic decay time in aortic pressure; $\beta$, partial regression coefficients; AASI, ambulatory arterial stiffness index; aPWV, aortic pulse wave velocity; AVCI, arterio-ventricular coupling index; MBP, mean blood pressure; $P$, significance of the partial regression coefficients; PP, pulse pressure; s.e., standard errors.

Variables that did not enter any regression model $(P$-value for entry $>0.15)$ include sex, body weight, smoking $(0,1)$, intake of alcohol $(0,1)$, previous antihypertensive treatment and the presence of the metabolic syndrome $(0,1)$.

Table 5 Concordance between indexes or arterial function at baseline

\begin{tabular}{|c|c|c|c|c|c|c|c|c|}
\hline & \multicolumn{4}{|c|}{$A A S I$} & \multicolumn{4}{|c|}{$a P W V$} \\
\hline & Unadjusted & $\mathrm{P}$-value & Adjusted & $\mathrm{P}$-value & Unadjusted & P-value & Adjusted & P-value \\
\hline 24-h PP (mm Hg) & 0.55 & $<0.001$ & 0.44 & $<0.001$ & 0.58 & $<0.001$ & 0.38 & $<0.001$ \\
\hline AASI (units) & 1 & & 1 & & 0.44 & $<0.001$ & 0.21 & 0.003 \\
\hline $\mathrm{aPWV}\left(\mathrm{ms}^{-1}\right)$ & - & & - & & 1 & & 1 & \\
\hline
\end{tabular}

Abbreviations: AASI, ambulatory arterial stiffness index; aPWV, aortic pulse wave velocity; PP, pulse pressure.

Values are correlation coefficients unadjusted or adjusted for sex, age, body height, $24-\mathrm{h}$ mean arterial pressure and the 24-h pulse rate. $P$-values indicate the significance of the correlation coefficients. 

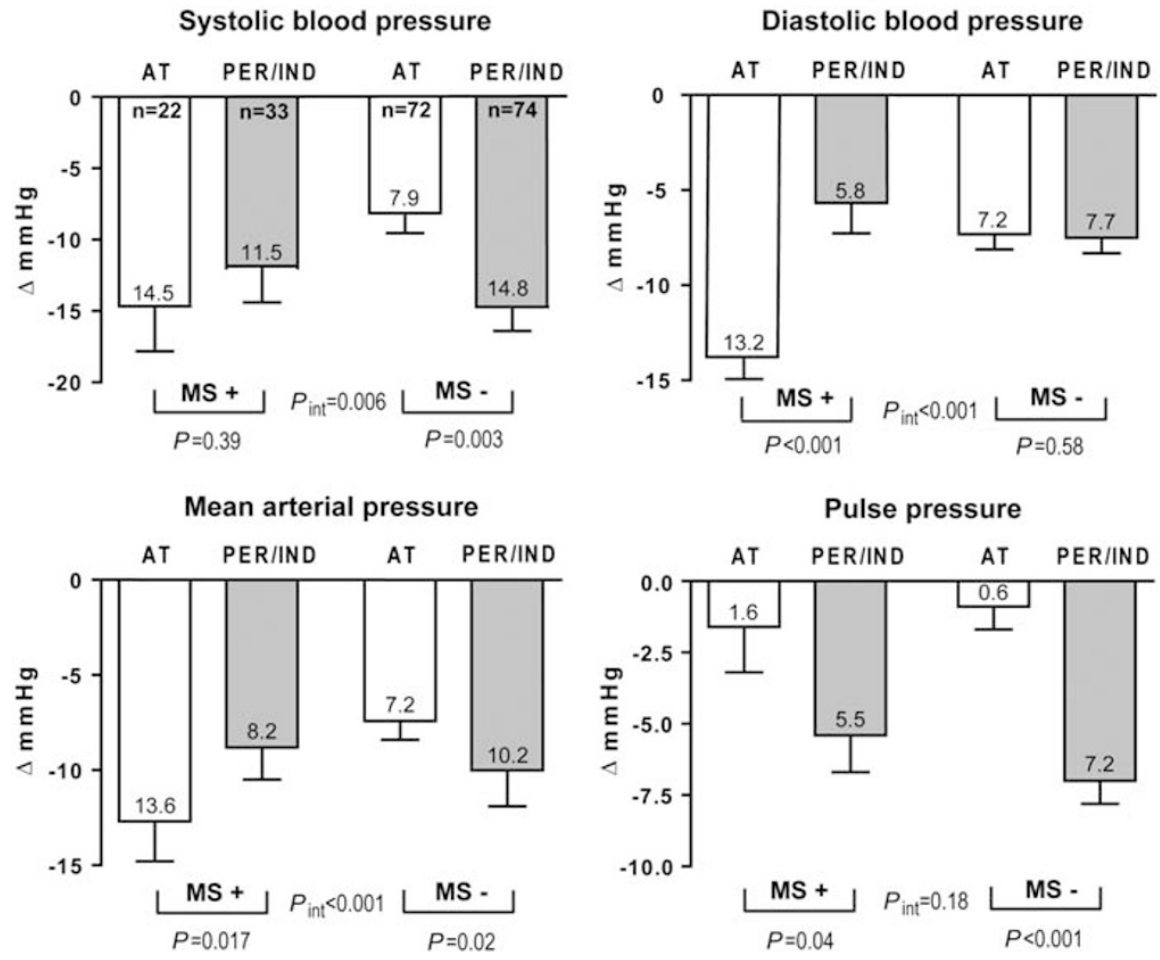

Figure 1 Changes in the 24-ambulatory blood pressure in response to 1 year of treatment with atenolol (AT) or perindopril/indapamide (PER/IND). Results are given for systolic and diastolic blood pressures, pulse pressure and mean arterial pressure in patients without (MS-) and with (MS+) the metabolic syndrome, defined according to the NCEP-ATPIII criteria. ${ }^{20} P$ denotes the significance of the treatment differences, $P_{\text {int }}$ the significance of the interaction between treatment and the MS, and $n$ the number of subjects in each group.

All other interaction terms of treatment with the MS were not statistically significant for BPs or the arterial indexes.

\section{DISCUSSION}

Both $\beta$-blockers and angiotensin-converting enzyme inhibitors reduce $\mathrm{BP}$, but through contrasting hemodynamic mechanisms. $\beta$-Blockers without intrinsic sympathomimetic activity, such as AT, decrease heart rate and cardiac output and increase total peripheral resistance, although the latter effect is blunted in the long-run. ${ }^{22}$ Angiotensinconverting enzyme inhibitors, such as perindopril, cause vasodilatation with inhibition of the reactive neurohumoral activation, increase muscular blood flow and have no negative inotropic effect on the myocardium. ${ }^{23}$ aPWV, which is determined in the most pulsatile segment of the arterial circulation, ${ }^{24}$ is the gold standard for measuring arterial stiffness. ${ }^{8}$ AASI is also determined at an arterial site with pulsatile flow, the brachial artery, but is an indirect measure of arterial function. ${ }^{8}$ AASI is also influenced by other hemodynamic factors, such as heart rate, ${ }^{1,25}$ stroke volume, wave reflections and systolic augmentation, and might also reflect arterio-ventricular coupling. ${ }^{10}$ However, after 1 year of treatment in the current study, the change in both aPWV and AASI were similar in the two treatment groups. Thus, under treatment with drugs with quite different hemodynamic profiles, AASI behaved similarly as aPWV.

Atenolol lowered systolic BP and PP less than PER/IND. As previously highlighted by other researchers ${ }^{22}$ and ourselves, ${ }^{12,13}$ this difference is largely the consequence of the AT-induced reduction of heart rate, which is responsible for a return of the wave reflections in the central arteries during systole. This timing precludes a lowering of the central systolic blood pressure. Our current results are in keeping with those of the Conduit Artery Function Evaluation ancillary study $^{26}$ from the Anglo-Scandinavian Cardiac Outcomes Trial. ${ }^{27}$ This sub-study included 2199 patients randomized to amlodipine with/without PER or to AT with/without bendroflumethiazide. ${ }^{26}$ Most patients received combination therapy throughout the study. Despite similar brachial systolic BPs between treatment groups (difference $(\Delta)$, $0.7 \mathrm{~mm} \mathrm{Hg}$; $95 \%$ confidence interval, -0.4 to $1.7 ; P=0.20$ ), there were substantial reductions in the aortic systolic BP $(\Delta, 4.3 \mathrm{~mm} \mathrm{Hg} ; 95 \%$ confidence interval, 3.3-5.4; $P<0.0001)$ and aortic $\mathrm{PP}(\Delta, 3.0 \mathrm{~mm} \mathrm{Hg}$; 95\% confidence interval, $2.1-3.9 ; P<0.0001)$ on the newer compared with the older drugs. Furthermore, under treatment with angiotensinconverting enzyme inhibitors, in particular PER, but not under treatment with AT, the structural arteriolar abnormalities associated with hypertension regress. ${ }^{28,29}$ The ensuing reduction of the reflection coefficients likely reduces the amplitude of the backward pressure wave and promotes a decrease of systolic BP and PP in the brachial artery.

In patients without MS, the reductions in the 24-h systolic BP and PP were significantly larger on PER/IND than on AT. The opposite trend occurred for diastolic BP in patients with the MS. In untreated hypertensive patients, structural alterations of the arterioles go hand in hand with capillary rarefaction. The MS and a positive sodium balance enhance capillary rarefaction. ${ }^{30-32}$ Angiotensin-converting enzyme inhibitors reverse the structural damage at the arteriolar level. Salt depletion by diet or the administration of diuretics restore capillary density. ${ }^{33}$ We hypothesize that these beneficial effects are more difficult to achieve in patients with the MS than in those without this condition. On the other hand, compared with PER/IND, AT produced a larger decrease in diastolic BP and mean arterial pressure in the patients with the MS than in those without this condition. This might be because of the longer diastole in the presence of vasodilatation, 
which generally occurs in the presence of obesity, ${ }^{34}$ one of the hallmarks of the MS. ${ }^{20}$

AASI reflects the dynamic relation between diastolic and systolic BP throughout the whole day, ${ }^{1,2}$ whereas aPWV and the 24-h PP do not account for the diurnal variability in the relation between diastolic and systolic BP. AASI depends on the combined effects of left ventricular ejection, the passive and active components of arterial stiffness and the reflection of the arterial pulse wave. In line with the present findings, we previously demonstrated that in healthy volunteers the unadjusted correlation coefficient between AASI and aPWV was $0.51 .^{1}$ Furthermore, in randomly recruited Chinese, both before and after adjustment for arterial wave reflections by considering height and heart rate as covariables, AASI correlated more closely with the central and peripheral systolic augmentation indexes than with the 24-h PP. ${ }^{1}$ In the current study, although accounting for covariables, AASI correlated significantly both with aPWV and the 24-h PP.

Our current study must be interpreted within the context of its potential limitations. First, the original sample size calculations for REASON considered aPWV as the main outcome measure for the comparison between AT and PER/IND. To detect a significant $(P=0.05)$ two-tailed difference of $0.5 \pm 1.2$ (s.d.) $\mathrm{m} \mathrm{s}^{-1}$ with $95 \%$ power, the number of subject to be analyzed was estimated to be 300 . The REASON trial overall included 471 subjects, but our current report included only 201 patients with an ambulatory BP recording of sufficient quality. To detect a between-group difference of $0.5 \pm 1.2 \mathrm{~m} \mathrm{~s}^{-1}$ with a two-sided $P$-value of 0.05 , our current study had $83 \%$ power. In addition, with a sample size of 201 , our current study had $95 \%$ power to detect a significant $(P=0.05)$ between-group difference in AASI of $0.066 \pm 0.13$ (s.d.) or more. We cannot exclude that our current analyses were underpowered. Nevertheless, our current findings were consistent with the previously published REASON results. ${ }^{12-14}$ Second, data from Framingham Study ${ }^{35}$ and the Atherosclerosis Risk in Communities study ${ }^{36}$ showed that lower HDLcholesterol was a forerunner of vascular disease. Although drinking alcohol increases HDL-cholesterol, ${ }^{37}$ in our current study HDLcholesterol at baseline was lower in PER/IND than in AT group. In a sensitivity analysis, we adjusted for HDL-cholesterol and for the small difference in the proportion of drinkers. However, we cannot exclude with certainty that residual confounding biased our results. Notwithstanding these potential limitations, compared with conventional BP measurement, ambulatory monitoring more precisely reflects a subject's usual blood pressure, excludes observer bias and minimizes the white-coat effect. ${ }^{4}$ These are desired characteristics that might contribute to the validity of AASI as an index reflecting the arterial function.

Our study is the first one to compare the influence of a pharmacological intervention on aPWV, the standard measurement of arterial stiffness $^{8}$ and AASI. On administration of antihypertensive drugs with quite different hemodynamic profiles, AASI and aPWV behaved similarly. Our current findings, taken together with the prognostic significance of AASI, ${ }^{2,6,7}$ and its concordance with other indexes of arterial function, ${ }^{1}$ strengthens the position of AASI as a diagnostic instrument reflecting arterial stiffness. A worldwide consortium of investigators are currently enlarging the database of ambulatory BP recordings in relation to cardiovascular outcomes and plan to study the predictive value of AASI in population-based cohorts of different ethnicity. ${ }^{38}$ In the meantime, manufacturers of devices for ABPM are including the computation of AASI in their software packages. Clinicians might consider AASI in the risk stratification of their patients under the proviso that further clinical and epidemiological validation of this novel prognostic index of arterial function is warranted.

\section{CONFLICT OF INTEREST}

The authors declare no conflict of interest.

\section{ACKNOWLEDGEMENTS}

We gratefully acknowledge the expert assistance of Ms Sandra Covens and Ms Ya Zhu. Sources of funding: research included in the present study was funded by the sponsor of the REASON trial (Servier, France) and partially by the Fonds voor Wetenschappelijk Onderzoek Vlaanderen, Brussels, Belgium (grants G.0575.06 and G.0734.09), and the Katholieke Universiteit Leuven, Leuven, Belgium (grants OT/04/34 and OT/05/49).

1 Li Y, Wang JG, Dolan E, Gao PJ, Guo HF, Nawrot T, Stanton AV, Zhu DL, O'Brien E, Staessen JA. Ambulatory arterial stiffness index derived from 24-h ambulatory blood pressure monitoring. Hypertension 2006; 47: 359-364.

2 Dolan E, Thijs L, Li Y, Atkins N, McCormack P, McClory S, O'Brien E, Staessen JA, Stanton AV. Ambulatory arterial stiffness index as a predictor of cardiovascular mortality in the Dublin Outcome Study. Hypertension 2006; 47: 365-370.

3 MacWilliam JA, Melvin GS. Systolic and diastolic blood pressure estimation with special reference to the auditory method. Br Med J 1914; 1: 693-697.

4 O'Brien E, Asmar R, Beilin L, Imai Y, Mancia G, Mengden T, Myers M, Padfield P, Palatini P, Parati G, Pickering T, Redon J, Staessen J, Stergiou G, Verdecchia P, on behalf of the European Society of Hypertension Working Group on Blood Pressure Monitoring. Practice guidelines of the European Society of Hypertension for clinic, ambulatory and self blood pressure measurement. J Hypertens 2005; 23: 697-701.

5 Leoncini G, Ratto E, Viazzi F, Vaccaro V, Parodi A, Falqui V, Conti N, Tomolillo C, Deferrari G, Pontremoli R. Increased arterial stiffness index is associated with target organ damage in primary hypertension. Hypertension 2006; 48: 397-403.

6 Hansen TW, Staessen JA, Torp-Pedersen C, Rasmussen S, Li Y, Dolan E, Thijs L, Wang JG, O'Brien E, Ibsen $\mathrm{H}$, Jeppesen J. Ambulatory arterial stiffness index predicts stroke in a general population. J Hypertens 2006; 24: 2247-2253.

7 Kikuya M, Staessen JA, Ohkubo T, Thijs L, Metoki H, Asayama K, Obara T, Inoue R, Li Y, Dolan E, Hoshi H, Hashimoto J, Totsune K, Satoh H, Wang JG, O'Brien E, Imai Y. Ambulatory arterial stiffness index and $24-h$ ambulatory pulse pressure as predictors of mortality in Ohasama, Japan. Stroke 2007; 38: 1161-1166.

8 Laurent S. Surrogate measures of arterial stiffness : do they have additive predictive value or are they only surrogates of a surrogate ? Hypertension 2006; 47: 325-326.

9 Benetos A, Lacolley PJ. From 24-h blood pressure measurement to arterial siffness: a valid short cut? Hypertension 2006; 47: 327-328.

10 Westerhof N, Lankhaar JW, Westerhof BE. The ambulatory arterial stiffness index is not a stiffness parameter but a ventriculo-arterial coupling factor. Hypertension 2007; 49: e7.

11 Hansen TW, Staessen JA, Torp-Pedersen C, Rasmussen S, Thijs L, Ibsen H, Jeppesen J. Prognostic value of aortic pulse wave velocity as index of arterial stiffness in the general population. Circulation 2006; 113: 664-670.

12 Asmar RG, London GM, O'Rourke ME, Safar ME. Improvement in blood pressure, arterial stiffness and wave reflection with a very-low-dose perindopril/indapamide combination in hypertensive patient : a comparison with atenolol. Hypertension 2001; 38: 922-926.

13 London GM, Asmar RG, O'Rourke MF, Safar ME, on behalf of the REASON project investigators. Mechanism(s) of selective systolic blood pressure reduction after a low-dose combination of perindopril/indapamide in hypertensive subjects: comparison with atenolol. J Am Coll Cardiol 2004; 7: 92-99.

14 Mallion JM, Chamontin B, Asmar R, de Leeuw PW, O'Brien E, Duprez D, O'Rourke MF, Rahn KH, Romero J, Battegay E, Hitzenberger G, Safar ME, on behalf of the REASON Project. Twenty-four-hour ambulatory blood pressure monitoring efficacy of perindopril/ indapamide first-line combination in hypertensive patients : the REASON study. Am J Hypertens 2004; 17: 245-251.

15 O'Brien E, Petrie J, Littler WA, de Swiet M, Padfield PL, Altman D, Bland M, Coats A, Atkins N. The British Hypertension Society protocol for the evaluation of blood pressure measuring devices. J Hypertens 1993; 11(Suppl 2): S43-S63.

16 The Association for the Advancement of Medical Instrumentation. American National Standard for Electronic or Automated Sphygmomanometers. The Association for the Advancement of Medical Instrumentation: Washington DC, USA, 1987

17 Kikuya M, Hansen TW, Thijs L, Björklund-Bodegård K, Kuznetsova T, Ohkubo T, Richart T, Torp-Pedersen C, Lind L, Ibsen H, Imai Y, Staessen JA, on behalf of the International Database on ambulatory blood pressure in relation to Cardiovascular Outcome (IDACO) investigators. Diagnostic thresholds for ambulatory blood pressure monitoring based on 10-year cardiovascular risk. Circulation 2007; 115: 2145-2152.

18 Nichols WW, O'Rourke M (eds). Contours of pressure and flow waves in arteries. In: McDonalds Blood Flow in Arteries. Theoretical, Experimental and Clinical Principles, 5th edn. Hodder Arnold: London, UK, 2005, pp 165-191.

19 Westerhof N, Elzinga G. Normzlized input impedance and arterial decay time over heart period are independent of animal size. Am J Physiol 1991; 261: R126-R133.

20 Expert Panel on the Identification Evaluation and Treatment of Overweight in Adults. Clinical guidelines on the identification, evaluation, and treatment of overweight and obesity in adults : executive summary. Am J Clin Nutr 1998; 68: 899-917. 
21 Satoh H, Kishi R, Tsutsui H. Metabolic syndrome is a significant and independent risk factor for increased arterial stiffness in Japanese subjects. Hypertens Res 2009; 32 : 1067-1071.

22 van den Meiracker AH, Man in 't Veld AJ, Boomsma F, Fischberg DJ, Molinoff PB, Schalekamp MADH. Hemodynamic and $\beta$-adrenergic receptor adaptations during long-term $\beta$-adrenoceptor blockade. Studies with acebutolol, atenolol, pindolol, and propranolol in hypertensive patients. Circulation 1989; 80: 903-914.

23 López-Sendón J, Swedberg K, McMurray J, Tamargo J, Maggioni AP, Dargie H, Tendera $M$, Waagstein F, Kjekshus J, Lechat P, Torp-Pedersen C. Expert consensus document on angiotensin converting enzyme inhibitors in cardiovascular disease. The task force on ACE-inhibitors of the European Society of Cardiology. Eur Heart J 2004; 25: 1454-1470.

24 Safar ME, Struijker Boudier H. Vascular development, pulse pressure, and the mechanisms of hypertension. Hypertension 2005; 46: 205-209.

25 Adiyaman A, Dechering DG, Boggia J, Li Y, Hansen TW, Kikuya M, Björklund-Bodegård K, Richart T, Thijs L, Torp-Pedersen C, Ohkubo T, Dolan E, Imai Y, Sandoya E, Ibsen H, Wang J, Lind L, O'Brien E. Thien T, Staessen JA, on behalf of the International Database on ambulatory blood pressure in relation to Cardiovascular Outcome (IDACO) investigators. Determinants of the ambulatory arterial stiffness index in 7604 subjects from 6 populations. Hypertension 2008; 52: 1038-1044.

26 Williams B, Lacy PS, Thom SM, Cruickshank K, Stanton A, Collier D, Hugues AD, Thurston H, O'Rourke M. Differential impact of blood pressure-lowering drugs on central aortic pressure and clinical outcomes : principal results of the Conduit Artery Function Evaluation ( CAFE) study. Circulation 2006; 113: 1213-1225.

27 Dahlöf B, Sever PS, Poulter NR, Wedel H, Beevers DG, Caulfield M, Collins R, Kjeldsen SE, Kristinsson A, McInnes GT, Mehlsen J, Nieminen M, O'Brien E, Östergren J. Prevention of cardiovascular events with an antihypertensive regimen of amlodipine adding perindopril as required versus atenolol adding bendrofluethiazide as required, in the Anglo-Scandinavian Cardiac Outcomes Trial-Blood Pressure Lowering Arm (ASCOT-BPLA) : a multicentre randomised controlled trial. Lancet 2005; 366: 895-906.

28 Thybo NK, Korsgaard N, Eriksen S, Christensen KL, Mulvany MJ. Dose-dependant effects of perindopril on blood pressure and small-artery structure. Hypertension 1994; 23: 659-666.
29 Schiffrin EL, Deng LY, Larochelle P. Effects of a $\beta$-blocker or a converting enzyme inhibitor on resistance arteries in essential hypertension. Hypertension 1994; 23: 83-91.

30 Frisbee JC. Hypertension-independant microvascular rarefaction in the obese Zucker rat model of the metabolic syndrome. Microcirculation 2005; 12: 383-392.

31 Stepp DW, Pollock DM, Frisbee JC. Low-flow vascular remodeling in the metabolic syndrome X. Am J Physiol Heart Circ Physiol 2004; 286: H964-H970.

32 De Jongh RT, Serne EH, Ijzerman RG, De Vries G, Stehouwer CD. Impaired microvascular function in obesity: implications for obesity-associated microangiopathy, hypertension, and insulin resistance. Circulation 2004; 109: 2529-2535.

33 Levy BI, Duriez M, Samuel JL. Coronary microvasculature alteration in hypertensive rats. Effect of treatment with a diuretic and an ACE inhibitor. Am J Hypertens 2001; 14: 7-13.

34 Zebekakis PE, Nawrot T, Thijs L, Balkestein EJ, van der Heijden-Spek J, Van Bortel L, Struijker-Boudier HA, Safar ME, Staessen JA. Obesity is associated with increased arterial stiffness from adolescence until old age. J Hypertens 2005; 23: 1839-1846.

35 Castelli WP, Garrison RJ, Wilson PWF, Abbott RD, Kalousdian S, Kannel WB. Incidence of coronary heart disease and lipoprotein cholesterol levels. JAMA 1986; 256: 2835-2838.

36 Sharrett AR, Ballantyne CM, Coady SA, Heiss G, Sorlie PD, Catellier D, Patsch W. Coronary heart disease prediction from lipoprotein cholesterol levels, triglycerides, lipoprotein(a), apolipoproteins A-I amd B, and HDL density subfractions. Circulation 2001; 104: 1108-1113.

37 Rimm EB, Williams P, Fosher K, Criqui M, Stampfer MJ. Moderate alcohol intake and lower risk of coronary heart disease:meta-analysis of effects on lipids and haemostatic factors. Br Med J 1999; 319: 1523-1528.

38 Thijs L, Hansen TW, Kikuya M, Björklund-Bodegård K, Li Y, Dolan E, Tikhonoff V, Sleidlerová J, Kuznetsova T, Stolarz K, Bianchi M, Richart T, Casiglia E, Malyutina S, Filipovskỳ J, Kawecka-Jaszcz K, Nikitin Y, Ohkubo T, Sandoya E, Wang JG, Torp-Pedersen $\mathrm{C}$, Lind L, Ibsen $\mathrm{H}$, Imai $Y$, Staessen JA, on behalf of the IDACO Investigators. The International Database of Ambulatory blood pressure in relation to Cardiovascular Outcome (IDACO) : protocol and research perspectives. Blood Press Monit 2007; 12: 255-262. 